\title{
Presence and Performance of Women in Higher Music Studies in Spain
}

\author{
Miguel Ángel Jiménez-Pérez ${ }^{\text {, Ana María Díaz-Olaya² }}$ \\ ${ }^{1}$ Real Conservatorio Superior de Música "Victoria Eugenia”, Granada, Spain \\ ${ }^{2}$ Área de Didáctica de la Expresión Musical de la Universidad de Málaga, Málaga, Spain \\ Email: majimenezp@gmail.com, anadiaola@uma.es
}

How to cite this paper: Jiménez-Pérez, $M$. Á., \& Díaz-Olaya, A. M. (2021). Presence and Performance of Women in Higher Music Studies in Spain. Open Journal of Social Sciences, 9, 455-469. https://doi.org/10.4236/jss.2021.95025

Received: April 20, 2021

Accepted: May 22, 2021

Published: May 25, 2021

Copyright (c) 2021 by author(s) and Scientific Research Publishing Inc. This work is licensed under the Creative Commons Attribution International License (CC BY 4.0)

http://creativecommons.org/licenses/by/4.0/

\begin{abstract}
This article is a case study focused on a music conservatory in southern Spain regarding the implications of the female gender in the academic and professional performance of music students. Through study of data from the Ministry of Culture, the center's secretariat and a more extensive survey carried out on the promotions of students who have completed their studies, it has been possible to observe a number of aspects showing a series of significant differences in terms of academic and professional performance between male and female music students, without concluding there is real discrimination.
\end{abstract}

\section{Keywords}

Conservatoire, Music Studies, Gender Discrimination

\section{Introduction}

There are few studies on the relationship between higher music studies and gender. The most significant are presented below, based on the specific subject matter they deal with.

One of the most studied aspects in this line is the relationship between gender and choice of instrument Pizarro (2010) speaks of a series of instruments traditionally considered masculine, such as brass or percussion instruments, and others more feminine, such as the piano or stringed instruments. Pégourdie (2015) and O'Neill and Boultona (1996) agree. The latter also states there are certain prejudices even from an early age when it comes to assessing which instruments are appropriate for either sex.

A second aspect in which men and women differ within the artistic profession concerns anatomy. Kok, Huisstede, and Nelissen (2017) show that female instrumentalists are more exposed to injuries resulting from practice and are more 
vulnerable than men.

Possible gender-related employment discrimination among professional instrumentalists has also been studied. Thus, Ravet and Coulangeon (2003), Coulangeon, Ravet and Roharik (2005) and Ramos (2010) study both vertical and horizontal segregation among professional performers and show how women tend to be more relegated to certain roles and generally occupy lower paid and less prestigious positions. Ravet and Coulangeon (2003) also add that, in addition to this greater employment precariousness, there is a larger occupation of part-time positions.

Within artistic careers, Coulangeon et al. (2005) point out that women suffer greater vulnerability in their working conditions, which makes them less likely to survive in the profession, as also stated by Alper and Wassall (2006). One aspect influencing this may be the different social roles played by women. In this regard, Teague and Smith (2015) point out that family obligations to a great degree condition the performance of artistic careers in women.

However, apart from these studies, not much more is known about the different behavior between genders within the conservatory.

We want to know what other characteristics, if any, make the difference between men and women within music studies in a conservatory such as the Royal Superior Conservatory of Music of Granada and that is presented as a case study that can serve as a sample of what is happening in these centers in Spain.

\section{Method}

\subsection{Design}

Taking the problem into account, and the aim of the research and questions derived from it, we have chosen to position the study within the phenomenological or interpretative paradigm. We have done so in order for the subjective and social reality of the research to more richly constructed with individual and collective contributions of all subjects involved, in which it is important to consider the feelings, attitudes and perceptions of participating students.

The study is performed in three phases: In the first, a qualitative study is done through which data extracted from the Cultural Statistics Yearbook supplied every year by the Ministry of Culture and Sport is described and interpreted.

In a second phase, a qualitative study is conducted with data from the registration books of the Royal Conservatory of Music "Victoria Eugenia" of Granada (RCSMVE).

As for the third phase, the case study focused on the RCSMVE, we proceed to the extraction of information through a descriptive qualitative/quantitative study, aiming to collect quantifiable information to be used in the statistical analysis of students responding to a questionnaire, making a compilation and description of data extracted from the surveys.

The sources from which the information will be extracted are the following:

1) Data available in the Yearbook of Cultural Statistics supplied annually by 
the Ministry of Culture and Sport.

2) Center Enrollment books.

3) The survey conducted in 2018 among conservatory graduates over the previous fifteen years.

\subsection{Research Objectives}

Taking the RCSMVE as the object of study, the following general research objectives are proposed, to which we intend to respond by relating the results obtained from the three research phases mentioned above:

1) Carry out an exploratory study of the characteristics of conservatory students to detect different behaviors between men and women;

2) To study the cause of these differences;

3) To detect if any type of discrimination or difference has a negative influence on women.

\subsection{Sample}

In the first case, the population under study is the entire conservatory student body in Spain, distributed among the three main teaching groups (elementary, professional and higher), with the exception of the data from the elementary centers in Catalonia, which do not appear in the report. The data of men and women of different levels throughout the historical series that includes the courses 2002/2003 to 2016/2017 have been gathered and conveniently extracted. The statistic has as its population the nearly 100,000 students per year who study in the different stages. In the 2016/2017 academic year, the students were 43,876 in Elementary Education, 46,907 in Professional or Intermediate and 8,788 in Higher Education (Anuario de Estadísticas Culturales: 2018: p. 188).

In the second case, the study population is the totality of students enrolled in the RCSMVE during the 2018/2019 academic year. On this occasion, it is 467 students who appear in a dispersed manner and who have been classified by specialties and gender for analysis.

Finally, the survey of conservatory graduates comprises a sample of students who responded to a questionnaire previously validated by a group of experts and that sought to obtain information on the integration that graduates experienced in the labor market. The aforementioned survey was given during March to April 2018 to all students who could be contacted and who met the condition of completing their studies at the center over the previous 15 years. From approximately 750 students, a total of 218 surveys were collected through the Google Forms application, corresponding to 115 men and 103 women.

\subsection{Research and Data Processing Instruments}

The different data were processed with programs such as Excel, for counting and graphing, and SPSS for more advanced statistical analysis. In the latter case, descriptive statistics, bivariate statistics by means of the Chi-square test and factor analysis and linear regression techniques were used. The Chi-square test is a 
hypothesis test that compares the distribution of two variables and is used to accept the hypothesis that both are independent (null hypothesis) or are related (alternative hypothesis). The p statistic is used as a measure of the probability of rejecting the alternative hypothesis when it is true. Thus, a value $p<0.05$ leads to accepting that the variables are related. On the other hand, factor analysis has been used to reduce a large set of variables to a smaller one but maintaining the same characteristics. In this case, a group has been created that contains part of the basic EU competencies both social and civic, cultural awareness and expression, learning to learn and communication in the mother tongue. This group of competencies therefore has common features. Linear regression is another statistical technique used that allows the prediction of one measure based on knowledge of others. In this case, when it was clear that the factorial reduction cited above conditions the sex variable.

Finally, qualitative analysis techniques were used to configure groups of subjects that students felt were lacking in the graduates' survey. Thus, the unstructured set of data formed by all the proposed subjects was classified through the Atlas.ti program into a series of categories enabling it to be treated more adequately from a quantitative point of view. In our case, a category was created that we called ergonomics/psychology to include suggestions of subjects made by graduates such as psychology for musicians, emotional intelligence or stage anxiety, ergonomics itself, Alexander Technique or yoga for musicians.

\section{Results}

\subsection{Presence of Women in Higher Education}

In a first phase, the data provided by the Cultural Statistics Yearbook (2002 to 2018) have been studied. Figure 1 summarizes the representation of women throughout different school years and different grades.

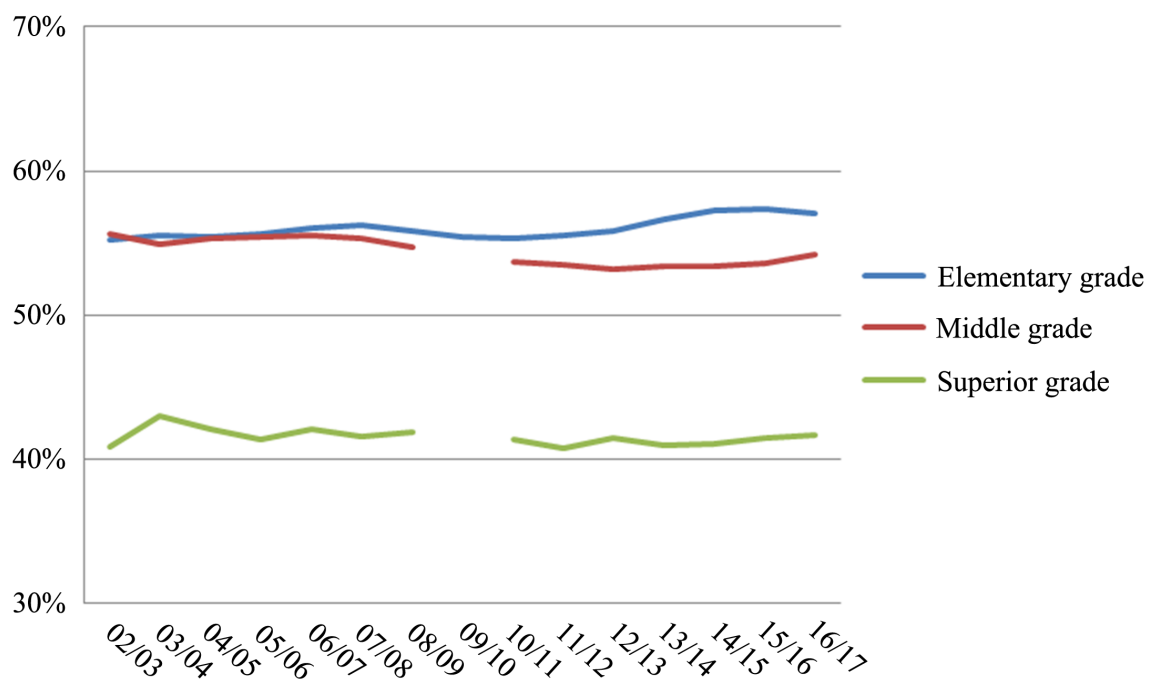

Figure 1. Women in music studies. Source: Anuario de estadisticas culturales. Own elaboration. 
As can be seen, there is a predominant presence of women, around $55 \%$ in the elementary and middle grades, but this drops to $40 \%$ in the higher grades. We are providing more attention to some studies that when changed from professional to higher level show a considerable decrease in the participation of women. Furthermore, it is these higher studies that qualify both women and men professionally to occupy jobs such as teachers.

We also offer data from the above-mentioned yearbook, such as the proportion of female professors in the different stages. According to the Anuario de Estadísticas Culturales (2018: p. 195) this proportion is $39.9 \%$. We believe that this data is of interest since the current qualification as a conservatory teacher is achieved by means of the Título Superior, that is, that obtained following completion of studies of Grado Superior. We can see that the percentage of women working as teachers is similar to that of women studying for the Grado Superior.

The Yearbook of Cultural Statistics does not provide more detail regarding student gender.

We have studied the RCSMVE enrollment book to obtain more information. The data is organized by gender and major. Based on that, we ascertain the number of women who carried out Higher Degree studies in this center during the $2018 / 2019$ academic year is 218 , representing $47 \%$ of the total number of students slightly higher than the percentage of women from the above-mentioned yearbook.

\subsection{Instrument Preference}

The Higher Studies of Music in Spain are organized in different specialties. In the case of the RCSMVE, its recognized specialties are Composition, Pedagogy, and Performance, to which the recently incorporated Conducting is added. In turn, Performance specialty is divided into different instrumental itineraries.

We wish to see how specialties are characterized according to student gender and analysis of books (Figure 2).

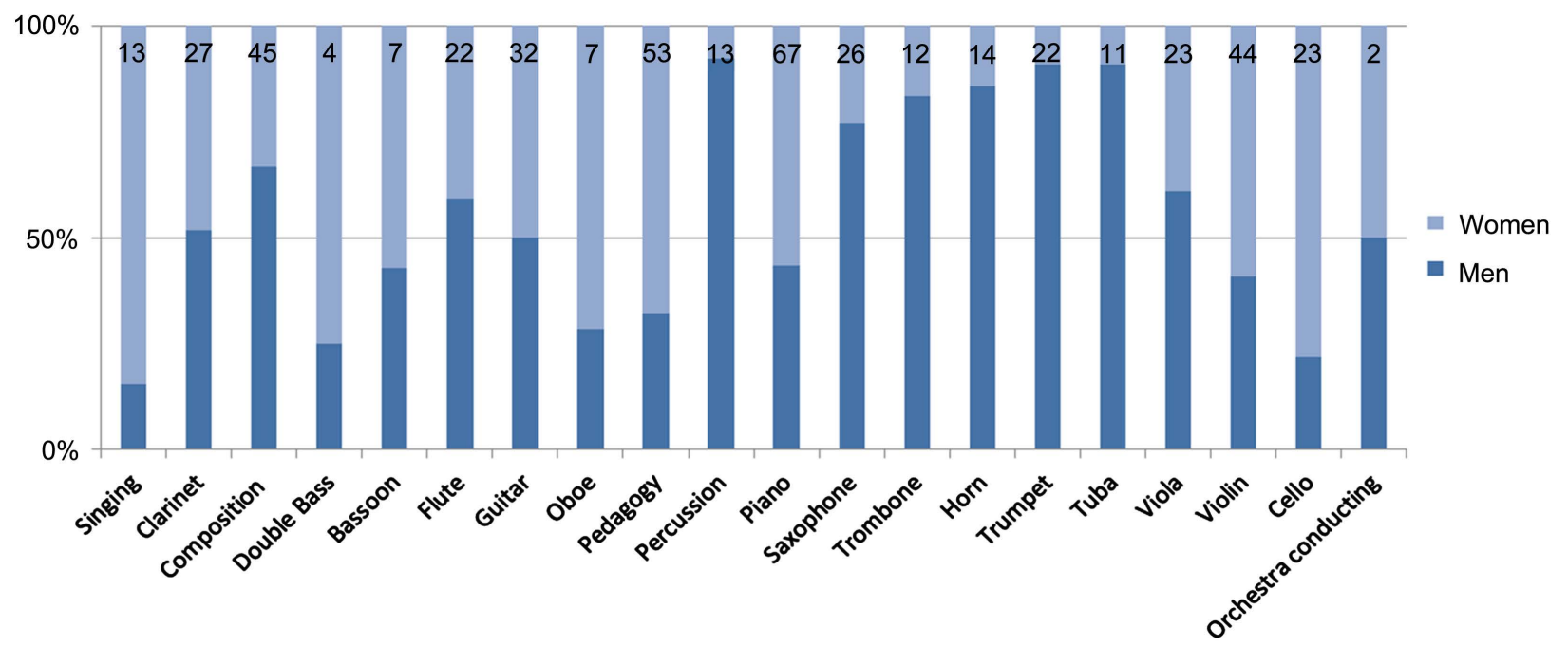

Figure 2. Percentage of students by sex and instrument. RCSMVE center enrollment books. Own elaboration. 
In this standardized graph, the percentage of men and women per instrument is shown together with the number of students per specialty (above the bar). It can be seen that some instruments are highly conditioned by gender. This is the case of brass instruments (Trombone, Trumpet, Trumpet and Tuba) and percussion, which are studied mostly by men, and to a lesser degree, the Composition specialty. On the other hand, women have a greater presence in specialties such as Singing, Cello, Double Bass and Oboe. In addition, there is a group with more balance between sexes, such as Clarinet, Bassoon, Flute, Guitar, Piano, Violin, Viola and Orchestra Conducting.

Finally, another source of information corresponds to the data obtained from the aforementioned survey of graduates. In this case, from all information provided by these students, we were interested in relationships where the sex variable provides information. These relationships have been obtained by systematically crossing the sex variable with the rest of the variables and selecting relationships that, once the Chi-square test was applied, were significant $(p<0.05)$ or highly significant $(p<0.01)$.

\subsection{Curriculum and Graduate Studies}

The remaining information was obtained from the survey of RCSMVE graduates. We asked about subjects that students feel they lack. From the total number of suggestions made, a list was created and, following a qualitative analysis using Atlas.ti, various categories were created. Women, in a highly significant way $(p<0.01)$, feel they lack subjects that could be included in the aforementioned field, ranging from psychology to ergonomics (Table 1).

Another trait that appears in the alumni survey associated with women is their higher level of English compared to men. In a statistically significant way ( $p<$ 0.05), women have greater English B2 levels and slightly less in C1 and C2. In men the predominant level is $\mathrm{B} 1$ and to a lesser degree A1 and A2 (Figure 3).

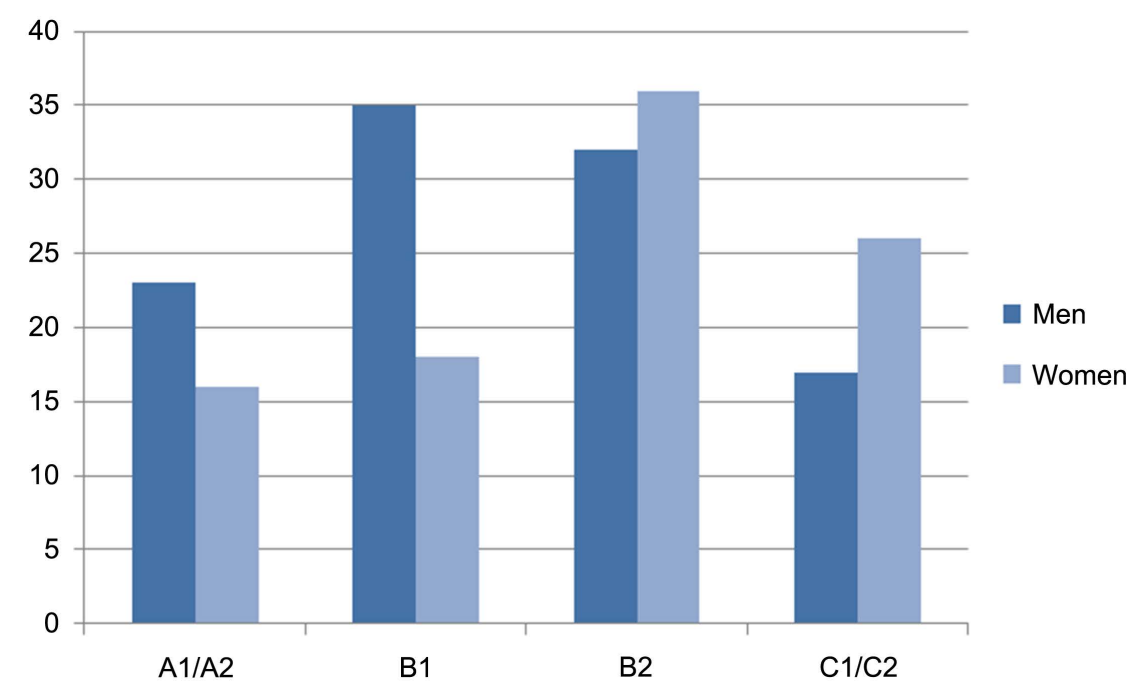

Figure 3. English level of RCSMVE graduates. Own elaboration. 
Table 1. Subjects in demand by RCSMVE graduates.

\begin{tabular}{cccc}
\hline & Men & Women & Significance $(p)$ \\
\hline Lack of ergonomics/psychology courses & 9 & 22 & 0.004 \\
\hline
\end{tabular}

Own elaboration.

In addition to this data, some features of the postgraduate studies that students undertake having completed their higher studies are characteristic. It must be said that higher studies in music are equivalent to undergraduate degrees and after completion they enable students to continue with postgraduate studies such as Master's, Doctorate or other types of studies. In our case, as well as Master's or Doctorate studies, we included language learning, expert courses or seminars as postgraduate studies. It is again women who show a statistically significant incidence in postgraduate studies such as language courses $(p<0.01)$ or seminars $(p<$ $0.05)$. The reasons why women pursue postgraduate studies are striking. To a large degree $(p<0.01)$ they do so to achieve greater specialization. It is therefore a sign that women in this postgraduate course seek specialization that conservatory studies do not provide and which is not so important for men (Table 2).

\subsection{Participation in Concerts}

Other data obtained from the survey that differentiates behavior between men and women is participation in concerts. This relationship is again highly significant $(p<0.01)$. It is characteristic that men show higher participation in concerts than women. Specifically, men tend to participate in more than ten concerts per year, while for women less than ten per year (Figure 4).

When asked about different styles, men are again statistically significant $(p<$ 0.05 ) more prone to this practice. Thus, it is not surprising that from this response, it appears that the practice of jazz among graduates is primarily male and to a highly significant degree $(p<0.01)$ (Table 3$)$.

\subsection{Competencies}

Finally, the survey asked graduates about the basic competencies mentioned by the EU and how they felt that mastery of these could help their integration into the labor market.

A factor analysis of the set of competencies regarding the sex variable was carried out obtaining a set of four competencies that tend to behave similarly in the case of women and significantly $(p<0.05)$. Thus, we can affirm that the group made up of social and civic competencies, cultural awareness and expression, learning to learn and communication in the mother tongue are perceived by women as those which, if mastered, might lead to better integration into the labor market.

\subsection{Income Level}

Variables such as monthly income or types of contract have also been analyzed. In the case of monthly income, we summarized in Figure 5. 


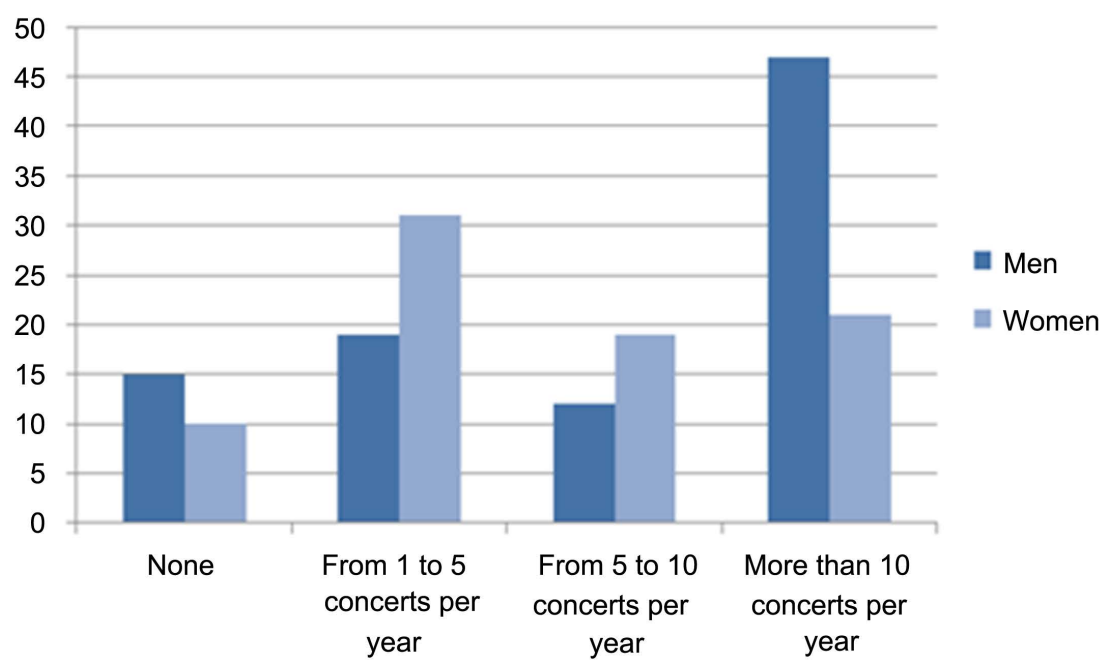

Figure 4. Participation of RCSMVE graduates in concerts. Own elaboration.

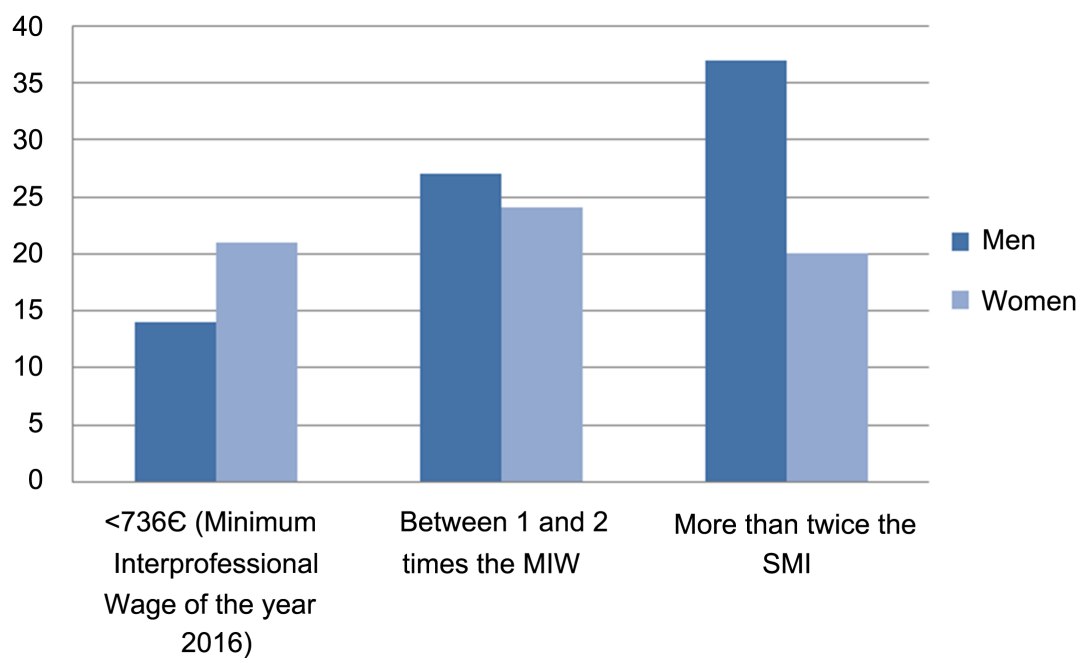

Figure 5. Percentage of income according to sex of RVSMVE graduates. Own elaboration.

Table 2. Postgraduate studies of RCSMVE graduates.

\begin{tabular}{cccc}
\hline & Men & Women & Significance $(p)$ \\
\hline Seminars as a postgraduate course & 45 & 55 & 0.035 \\
Language studies as a postgraduate course & 38 & 52 & 0.009 \\
Postgraduate studies for further specialization & 32 & 54 & 0.000 \\
\hline
\end{tabular}

Own elaboration.

Table 3. Practice of different styles by RCSMVE graduates.

\begin{tabular}{cccc}
\hline & Men & Women & Significance $(p)$ \\
\hline Practice of other styles & 60 & 36 & 0.016 \\
Jazz practice & 33 & 13 & 0.004 \\
\hline
\end{tabular}

Own elaboration. 
It can be seen that men have a higher percentage of occurrence in higher salaries although this relationship is not statistically significant.

\section{Discussion}

We are faced with a study whose object is teaching which has traditionally been quite neglected. The incorporation of the higher conservatories to the EHEA is still recent, therefore there is no great research tradition that could encourage work to be carried out on the centers themselves. In addition, the organic dependence of the Secondary Education system does not allow for an infrastructure that could help in labor orientation and subsequent follow-up of students who complete studies. Thus, the option of an exploratory study appears to be most appropriate for examining the various characteristics of each gender of students in the Higher Degree.

The first is the lower incidence of female students, unlike in elementary and middle school, where women are more numerous. It contrasts with the study of graduates from the University of Granada (Luque et al., 2014) which collects a large sample where percentage of women is $64.5 \%$ (p. 15). Lorenzo and Escandell (2003) study school dropout in elementary and professional or medium conservatories, and state it is one of the least studied phenomena but that due to its high incidence is worrying, especially in professional conservatories. We have no evidence that this dropout is different between men and women throughout the intermediate level, but perhaps the reasons for different enrollment in the higher level are due to the fact that the main cause of dropout during the intermediate level is accentuated, such as expectations created about studies.

Hargreaves, MacDonald and Miell (2012) state that musical development depends on the identity of individuals which is conditioned by society. Parkes and Jones (2011) opine regarding the decision to choose a career in performance, as students do not make this choice with the thought of becoming a teacher in mind (p. 20). This seems to indicate a predisposition to pursue a career in music in order to become a professional performer which might hold women back somewhat. In fact, from our own study it is apparent that men who have a more active participation in concerts.

We lack studies on the process of change from Professional to Higher Education. In the enrollment data we provide, a total of 46,907 students were studying Professional Education and a total of 8788, Higher Education. Without counting repetitions, we could make an approximation of about 7800 students per year in the Professional Degree and about 2200 students per year in the Higher Degree. There are therefore a large proportion of students who do not continue. In this approximation, only 35\% of Professional Degree students would continue their studies. As seen, dropout is very high in the professional studies themselves, especially as they advance and their general studies become more complicated. Causes given are various, but simultaneity with general studies appears to be one of the most determining factors. However, these dropouts during the Profes- 
sional Degree do not reflect a greater dropout of women, since the percentage of those enrolled is very similar to that of the Elementary Degree. Therefore, we believe that the high dropout of women occurs when they begin their higher education studies. The psychological aspect could be of some importance here. Bonneville-Roussy, Evans, Verner-Filion, Vallerand and Bouffard (2017) state that men and women react differently to stress (p. 4). This allows us to show a characteristic such as women are more prone to stress in events but nevertheless perform better in university or long-term studies. This could explain the lower attraction of women to a profession with a high stress content. It could also explain the lower participation in concerts as shown by the results.

In this search for characteristics of women in higher education, as a second trait, we can see that we can see that there is a difference with respect to men when it comes to identifying with and choosing an instrument. It is this instrument that forms a fundamental part of the degree and therefore marks and conditions the students like no other trait. And what we can see is that there are instrumental preferences conditioned by gender. This is the case of brass instruments that appear to us recurrently attributed to men which coincides with the vision of Pizarro (2010), Pégourdie (2015) and O’Neill and Boultona (1996). Those authors state that stringed instruments are more chosen by women. In our study this is the case except for the viola which is more studied by men. O'Neill and Boultona (1996) believe that women's choice of instrument is influenced by physical reasons (p. 180) and believe that some instruments are sexually stereotyped from childhood. In the case of men, they believe that the violin is the most appropriate instrument for women (p. 131). This predilection for certain instruments could imply that women have more difficulty integrating into bands, in which the presence of brass instruments is greater, and therefore reduce the possibility of participating professionally in these formations, which have a large tradition in Spain.

If we pay attention to the curriculum of the studies, conservatory graduates feel they lack subjects that respond to various criteria ranging from the need for pedagogical, theoretical-practical or inclusion in the labor market. This question brings to the forefront the debate that is present internationally on curriculum reform (Brook \& Fostaty Young, 2019) especially regarding how to adapt to the changing society. Subjects in particular in demand by women and in a statistically significant way are not those most requested by graduates but they can help us to understand specific needs requested by them. These are a group of subjects along the lines of care of the body and mind. It has been previously commented (Bonneville-Roussy et al., 2017) how women are more sensitive to stress than men, therefore subjects such as yoga, stage anxiety or psychology for musicians are a complement to their needs. Kok, Huisstede and Nelissen (2017: p. 544) point out that women are often more prone than men to injuries, especially in the case of musical practice. We believe that his specific need for subjects oriented to body care are in line with what previous authors present. 
The propensity of RCSMVE female students to take language courses and to have a high level of proficiency in these is striking. In our case, they have higher levels of English. In addition, they are characterized by a higher level of postgraduate training in English than men. The level of English in Spain according to EF (2018) is two points higher in women than in men (56.49 versus 54.5 points) generally considered intermediate. The report itself correlates high levels of English with good performance in research, business or talent. However, a study close to ours, such as that of graduates from the University of Granada, (Luque et al., 2014), shows that the level of English in men is statistically significantly higher than that of women (p. 134). This striking level of English among conservatory students, together with the special concern of women for graduate studies, could indicate an inclination of women towards more humanistic aspects of the degree than the eminently practical aspects of performance. In this sense, the survey of graduates from the University of Granada, Luque et al. (2014) shows us how women university students in Granada complete their studies in shorter time than men (p. 43) and do so with better records (p. 53). In addition, in a statistically significant way they show a greater interest in postgraduate studies (p. 175), greater preference for seminars and language courses as postgraduate (p. 199) or declare that they have undertaken postgraduate studies for reasons of usefulness (p. 240). This could also be a sign that women have more practical thinking. The survey of RCSMVE graduates showed that, regarding employment opportunities, about $70 \%$ of graduates' main occupation is teaching in centers such as conservatories, music schools, secondary schools, colleges or academies. The willingness of women to improve their training might be due to being more practical and realistic as regards integration into the labor market, despite being a career oriented towards interpretation, this is not easy for graduates. This problem is not only specific to RCSMVE students, but is shared internationally. We are at a time when the role of the musician is being redefined and where the idea of a broader profession that goes beyond the identification of musician with performer appears (Bennett, 2013; Munnelly, 2017; Parkes \& Jones, 2011; Vilar, 2008). In this redefinition of the role of musician, there is the idea of a sustainable career or portfolio, where the professional has a polyvalent profile enabling them to address a wider range of jobs roughly related to their profession. In this regard, Coulangeon, Ravet and Roharik (2005: p. 371) show that women artists are less willing to work in different simultaneous activities at the same time, thus they seem more reluctant about the idea of the portfolio profile. In our case, in the survey of conservatory graduates, it is perceived that conservatory respondents work mainly in the education sector although they remain relatively active at the performance level.

Income from artistic activity has also been observed. For the most part, income from performing is less than $10 \%$ of total activities. It is interesting to see how women participate in concerts to a lesser degree. In a statistically significant way $(p<0.01)$, women participate in fewer concerts than men. This may be due to greater risk aversion to that mentioned earlier. Family reconciliation more 
pronounced in women and especially at a certain age, might also be involved. Coulangeon et al. (2005: p. 369) indicate that women artists are gradually more vulnerable, but when working conditions are controlled (work and family life), they do not differ from men. Scharff (2015: p. 97) provides another data that might be related to lower participation of women in concerts referring to the fact they are more reluctant to promote themselves. In general, musicians see promotion work as having little to do with their artistic spirit, especially women. It is attributed that they are more modest in their work expectations, they believe that self-promotion is non-artistic and interferes with their inner self and they also believe that the idea of promoting their work can be somehow associated to prostitution.

Related to the above would be the minimal participation of women in a musical style such as jazz. Coulangeon et al. (2005: p. 373) show us certain discrimination in popular music groups where women are reduced to singing roles.

The answers provided by graduates on skills they consider useful toward better integration into the labor market also give us interesting clues to better understand the characteristics of female students in higher education. We have been able to identify a set of competencies leading us to believe they see their work as having a strong social service or more humanistic component. Thus, social and civic competencies, cultural awareness and expression, learning to learn and communication in the mother tongue appear as a group that is particularly characteristic of women. They also correspond to the greater interest and success in university studies that we witnessed previously. As mentioned, these are what the European Union calls basic competencies, but these are not the only ones. Pérez et al. (2018) warn of the low level of competencies of Spanish university students that hinder employability.

Finally, it is interesting to make a reference to the salary of RCSMVE graduates. We have seen that men move in higher salary bands than women. This data is similar to that of the graduates of the University of Granada (Luque et al., 2014) in which men have higher salaries (p. 374) and more stable contracts (civil servants or indefinite) (p. 374). Coulangeon et al. (2005: p. 372) state that, in the artistic professions, women are less well paid and suffer worse working conditions. The authors speak of strong horizontal and vertical discrimination among female performers.

As mentioned above, most conservatory graduates work in teaching. Very few make an exclusive living from performing. In this new redefinition of the role of musicians we have discussed, it would also be interesting to study whether there is any kind of segregation in the work most frequently performed by female musicians, such as teaching.

\section{Conclusion}

As a first aim, we set out to study the characteristics of the student body of higher conservatories. To this end, we studied data from the aforementioned Yearbook of Cultural Statistics and, more specifically, data from the enrollment book 
and study of graduates carried out at the RCSMVE, and paid particular attention to gender characteristics. We were able to ascertain a number of characteristics where men and women differ. We showed striking characteristics in terms of the percentage of women, instrument of study, suggestions on inclusion of subjects, relationship with other studies such as languages or postgraduate studies, participation in concerts, practice of different styles, valuation of competences or income level.

Regarding our second aim, for each of the above characteristics we attempted to see the causes why they occur. We were able to highlight studies similar to ours which served as reference. As an exploratory study, we outlined some reasons we believe these differences occur. In some aspects, we cannot categorically conclude. This is the case of the lower percentage of women in higher music studies, suggestions on certain subjects, different attitudes towards concerts, different practices of styles such as jazz or valuation of skills. In spite of detecting different behaviors between men and women, we believe that further studies are necessary to better understand why these occur. On the other hand, we have been able to see that there are certain aspects consistent with previous studies. This is the case of predilection for instruments according to gender or different attitudes towards postgraduate studies or women's lower income level. There is a striking difference in attitudes towards languages from conservatory students compared to those at the University of Granada.

As a final aim, we wished to see if there was any type of discrimination that might affect women. We understand that most of the traits we have shown do not presuppose discrimination between men and women, but rather respond to physical or psychological aspects that obviously affect and condition them differently. We understand that aspects where it is understood there exists certain discrimination were more worrying. This is the case of pay, which, as our study shows, is slightly lower for women than for men. We note that this difference is not exclusive to the music profession. Furthermore, we highlight changes we are experiencing regarding the idea of the profession of musician, which we believe may affect men and women differently. Further studies would be necessary to clarify this aspect in greater depth.

This study provides for the first time relevant information on the differences between men and women in higher music studies in Spain. Taking into account the special and minority nature of these studies, some data are provided that allow us to appreciate different characteristics between men and women and that can give rise to checking whether these traits are present in other higher artistic careers and in an element of comparison with rest of higher studies. In addition, it can help us to better understand the participation of women in the artistic activities of society.

\section{Conflicts of Interest}

The authors declare no conflicts of interest regarding the publication of this paper. 


\section{References}

Alper, N. O., \& Wassall, G. H. (2006). Chapter 23 Artists' Careers and Their Labor Markets. In V. A. G. D. Throsby (Ed.), Handbook of the Economics of Art and Culture (Vol. 1, pp. 813-864). Elsevier. https://doi.org/10.1016/S1574-0676(06)01023-4

Anuario de Estadísticas Culturales (2018). MECD: Ministerio de Educación Cultura y Deporte. https://doi.org/10.4438/030-15-291-3

Bennett, D. E. (2013). Understanding the Classical Music Profession: The Past, the Present and Strategies for the Future. Farnham: Ashgate Publishing, Ltd.

Bonneville-Roussy, A., Evans, P., Verner-Filion, J., Vallerand, R. J., \& Bouffard, T. (2017). Motivation and Coping with the Stress of Assessment: Gender Differences in Outcomes for University Students. Contemporary Educational Psychology, 48, 28-42. https://doi.org/10.1016/j.cedpsych.2016.08.003

Brook, J., \& Fostaty Young, S. (2019). Exploring Post-Degree Employment of Recent Music Alumni. International Journal of Music Education, 37, 142-155. https://doi.org/10.1177/0255761418821165

Coulangeon, P., Ravet, H., \& Roharik, I. (2005). Gender Differentiated Effect of Time in Performing Arts Professions: Musicians, Actors and Dancers in Contemporary France. Poetics, 33, 369-387. https://doi.org/10.1016/J.POETIC.2005.09.005

EF (2018). English Proficiency Index. http://www.ef.com/epi

Hargreaves, D. J., MacDonald, R., \& Miell, D. (2012). Musical Identities Mediate Musical Development. In G. E. McPherson, \& G. F. Welch (Eds.), Oxford Handbook of Music Education (Vol. 1, 125-142). Oxford: Oxford University Press. https://doi.org/10.1093/oxfordhb/9780199730810.013.0008

Kok, L. M., Huisstede, B. M. A., \& Nelissen, R. G. H. H. (2017). Musculoskeletal Complaints in Male and Female Instrumental Musicians. In Principles of Gender-Specific Medicine (pp. 543-556). Amsterdam: Elsevier. https://doi.org/10.1016/B978-0-12-803506-1.00030-9

Lorenzo, S., \& Escandell, M. O. (2003). El abandono de los estudios musicales en el Conservatorio Superior de Música de Las Palmas de Gran Canaria: La opinión de los profesores del Centro. Anuario de Filosofía, Psicología y Sociología, 6, 101-116.

Luque, T., Del Barrio, S., Fernández, J. S., \& Ibáñez, J. Á. (2014). Estudio de egresados de la Universidad de Granada. La inserción laboral en el Campus de Excelencia Internacional.

Munnelly, K. P. (2017). Understanding Career \& Degree Expectations of Undergraduate Music Majors. Columbus, OH: Ohio State University.

O’Neill, S. A., \& Boultona, M. J. (1996). Boys' and Girls' Preferences for Musical Instruments: A Function of Gender? Psychology of Music, 24, 171-183. https://doi.org/10.1177/0305735696242009

Parkes, K. A., \& Jones, B. D. (2011). Students' Motivations for Considering a Career in Music Performance. Update: Applications of Research in Music Education, 29, 20-28. https://doi.org/10.1177/8755123310397005

Pégourdie, A. (2015). L'instrumentalisation des carrières musicales Division sociale du travail, inégalités d'accès à l'emploi et renversement de la hiérarchie musicale dans les conservatoires de musique. Sociologie, 6, 321. https://doi.org/10.3917/socio.064.0321

Pérez, F., Aldás, J., Peiró, J. M., Serrano, L., Miravalles, M., Soler, Á., \& Zaera, I. (2018). Itinerarios de inserción laboral y factores determinantes de la empleabilidad: Formación universitaria versus entorno. Fundación BBVA.

Pizarro, C. U. (2010). Las mujeres de la música y la educación en México. In M. A. (Presidencia) Vollmer (Ed.), Congreso Iberoamericano de Educación: Metas 2021. Buenos 
Aires.

Ramos, P. (2010). Luces y sombras en los estudiossobre las mujeres y la música. Revista Musical Chilena, 64, 7-25. https://doi.org/10.4067/S0716-27902010000100002

Ravet, H., \& Coulangeon, P. (2003). La division sexuelle du travail chez les musiciensfrançais. Sociologie Du Travail, 45, 361-384. https://doi.org/10.1016/S0038-0296(03)00039-6

Scharff, C. (2015). Blowing Your Own Trumpet: Exploring the Gendered Dynamics of Self-Promotion in the Classical Music Profession. Sociological Review, 63, 97-112. https://doi.org/10.1111/1467-954X.12243

Teague, A., \& Smith, G. D. (2015). Portfolio Careers and Work-Life Balance among Musicians: An Initial Study into Implications for Higher Music Education. British Journal of Music Education, 32, 177-193. https://doi.org/10.1017/S0265051715000121

Vilar, J. M. (2008). Jóvenes músicos, formación académica y mundo laboral. Musiker, 16, 341-350. 